\title{
Fetal tibial and foot length for prediction of gestational age: An ultrasonographic study
}

\author{
Vishnu Datt Pandey ${ }^{1}$, Vishram Singh², G. L. Nigam ${ }^{3}$, Yasmeen ${ }^{4}$, Yogesh Yadav ${ }^{5, *}$ \\ ${ }^{1}$ Ph.D. Scholar, ${ }^{2}$ Professor and Head, ${ }^{5}$ Professor, ${ }^{1,2,5}$ Dept. of Anatomy, Santosh Medical College, Ghaziabad, Uttar Pradesh, \\ ${ }^{3}$ Associate Professor and Head, Dept. of Anatomy, LLRM Medical College, Meerut, Uttar Pradesh, ${ }^{4}$ Associate Professor and \\ Head, Dept. of Radiodiagnosis, SVBP Hospital, LLRM Medical College, Meerut, Uttar Pradesh, India
}

*Corresponding Author:

Email: yogeshyadav@msn.com

\begin{abstract}
Introduction: An accurate gestational age is must for Obstetricians and Gynecologists to make appropriate decisions, for identify and counseling women who are at risk of a preterm delivery and to evaluation of fetal growth and the detection of intrauterine growth restriction (IUGR). In our present study, we worked on fetal tibial length \& foot length and found that in normal growing fetus, fetal tibial length increase with advancing gestational age and regression analysis showed a strongly significant relationship between gestational age and fetal tibial length.

Materials and Methods: 100 pregnant women underwent ultrasonographic measurements of Tibia and Foot Length from 15 to 36 weeks of gestation, in the Radio diagnosis Department.

Results: In our study, we found the earliest age at which Tibia and foot length could be seen by ultrasound was 15 weeks of gestation and mean tibia length $10.25 \pm 0.50$, mean foot length is $17.5 \pm 1.29$ while at 36 weeks of gestation are $70.80 \pm 0.84$ and $64.4 \pm 3.28$ respectively. A strongly significant relationship has been observed between fetal foot length and gestational age by regression analysis.

Conclusion: Fetal tibia length and foot length can be considered as one of the good parameter for the determination of gestational age.
\end{abstract}

Keywords: Fetal tibial length, Fetal foot length, Gestational age by USG.

\section{Introduction}

Precise pregnancy dating is important in the interpretation of biochemical serum screening test or for guiding patients about the option of termination of pregnancy. ${ }^{1}$ Clinical parameters such as the menstrual cycle or uterine size often are not reliable so ultrasound is considered the most precise parameter for pregnancy dating by the obstetrician. Ultrasound is a veracious and practical modality for the assessment of gestational age and, as a routine part of prenatal care, can modify obstetric management and improve antepartum care. For last $\sim 40$ years, the relationship between various fetal biometric parameters such as gestational sac mean diameter, crown rump length, femur length (FL), biparietal diameter (BPD) \& abdominal circumference (AC) and gestational age have been described. Early antenatal ultrasound has been proven as an objective and precise tool for establishing gestational age. ${ }^{1}$ Underestimation of gestational age might occurred due to underestimation of FL in cases femur achondroplasia has a characteristic pattern of normal growth of fetal foot observed by Streeter in 1920 and proposed that it could be used as tool to estimate gestational age. ${ }^{2}$

The development of the foot described under 4 stages by Boehm ${ }^{3}$ as follows:

1. Stage one ( $2^{\text {nd }}$ month): The foot is in 90 degrees equinus and adducted.
2. Stage two (beginning of $3^{\text {rd }}$ month): The foot is in 90 degrees equinus, adducted and markedly supinated.

3. Stage three (middle of $3^{\text {rd }}$ month): The foot dorsiflexes at the ankle, but a mild degree of equinus is still present and marked supination persists. The first metatarsal remains adducted. This stage corresponds to the fetal period of development.

4. Stage four (beginning of $4^{\text {th }}$ month): The foot pronates and reaches a position of Mid-supination. A slight metatarsus varus remains. The equinus is absent. ${ }^{3}$

In cases of hydrocephalus, anencephaly or shortlimb dwarfism fetal foot length observed by Mercer et $a l .^{4}$ as a reliable parameter for the estimation of gestational age and particularly useful when other parameters cannot accurately predict gestational age.

Thus, the purpose of this study is to determine the accuracy of fetal foot length in estimating gestational age and correlating it with the previously approved parameters such as biparietal diameter, femur length and abdominal circumference.

The ultrasonic evaluation of morphometry of the long bones of the limbs is being increasingly utilized for fetal development and diagnosis of fetal anomalies. ${ }^{5}$

All of the extremities bone lengths correlate with gestational age and may used as indicators of skeletal dysplasia. Extensive study has been done by femur length, biparietal diameter and abdominal 
circumference in Indian population for the assessment of gestational age. But the data regarding the tibial length in Indian population is meagre. Fetal tibial length measurement can be utilised as an accurate parameter to determine gestational age.

Objectives of the present study were to determine the fetal tibial length at various stages which corresponds to gestational age. A comparative evolution of fetal tibial length verses BPD (Bi Parietal diameter) AC (Abdominal Circumference) and FL (Femur Length) was also done and fetal tibial length was determined in estimating gestational age in $2^{\text {nd }}$ and $3^{\text {rd }}$ trimester.

\section{Materials and Methods}

The present study is observational prospective type of study. The study was conducted in the Department of Anatomy, Santosh Medical College \& Hospital, Ghaziabad, NCR in coordination with the Department of Anatomy \& Radio diagnosis L.L.R.M Medical College, Meerut (U.P.), in pregnant women attending the OPD during 2nd and 3rd trimester for routine checkups. The present study was done in 100 normal pregnant women who were sure about their last menstrual period, had regular menstrual cycle, not experienced any vaginal bleeding since becoming pregnant; no one had taken oral contraceptives for at least 3 months before conception, having singleton apparently normal fetuses between 15 to 36 weeks of gestation and no medical pathology.

Ultrasonographic measurements of Tibia and Foot were done (Fig. 1 and Fig. 2) without prior knowledge of gestational age and then the gestational age was confirmed by an early abdominal ultrasound by biparietal diameter, femur length and abdominal circumference. The standard methods of obtaining the foot length, biparietal diameter, femur length and abdominal circumference were employed.

Allmeasurements were made by scanning thepatients using a new Medison SA 8000 SE ultrasonographic machine by a single skilled and experienced sonologist.

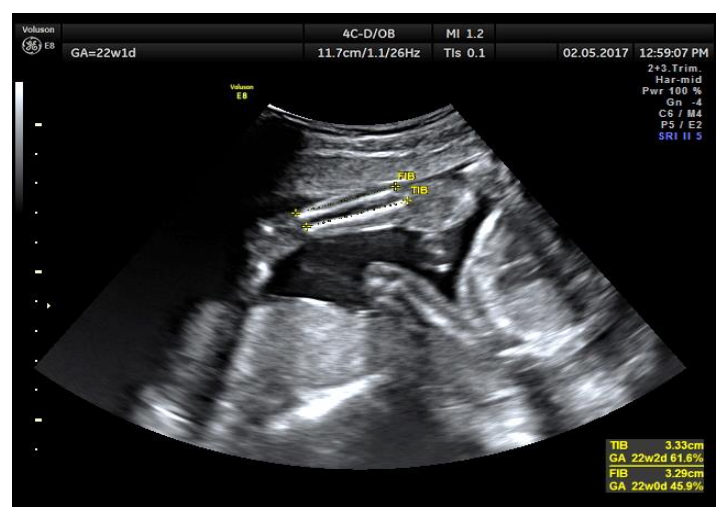

Fig. 1: Ultrasonographic image of tibia length

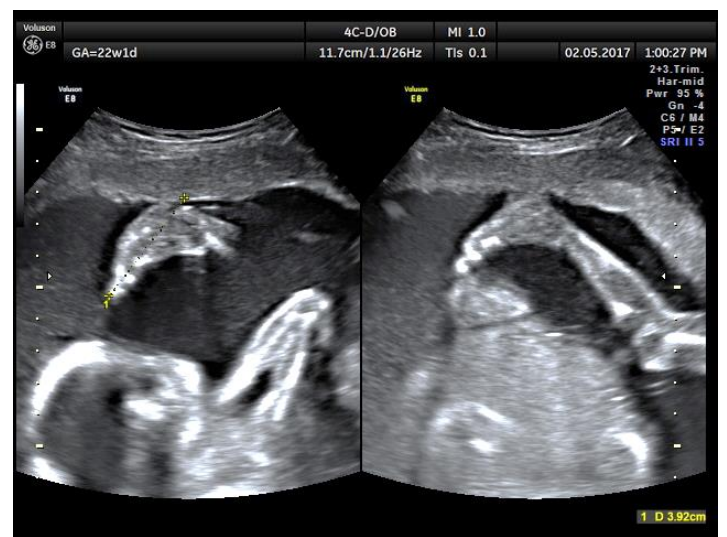

Fig. 2: Ultrasonographic image of foot length

\section{Results}

The foot length from 15 to 36 weeks of gestation was measured by sonography. In present study the earliest age at which fetal foot length could be seen sonographically was found to be 15 weeks of gestation and mean foot length is $17.5 \pm 1.29$ and mean sonographic foot length at 36 weeks of gestation is $64.4 \pm 3.28$ (Table 1). Along with foot length biparietal diameter (BPD), femur length (FL), abdominal circumference (AC) also measured for comparison (Table 1).

From regression analysis a strongly significant relationship has been observed between fetal foot length and gestational age (Table 2).

$$
\mathrm{y}=7.130+0.503 \mathrm{x}
$$

where, $\mathrm{y}=$ gestational age in weeks

$\mathrm{x}=$ foot length in $\mathrm{mm}$

Graphical representation of linear correlation between tibial length and gestational age was as per Graph 1. The graph represented as linear correlation between the two parameters.

Comparative plot of TL, FL, BPD, AC against gestational age was as per Graph 2.

From regression analysis a strongly significant relationship has been observed between fetal tibial length and gestational age.

$\mathrm{Y}=9.117+0.371 \mathrm{X}$

where $\mathrm{y}=$ gestational age in weeks, $\mathrm{X}=$ tibial length in mm. 
Table 1: The mean values and standard deviation of foot length (FTL), biparietal diameter (BPD), femur length (FL), and abdominal circumference (AC) at weekly intervals from 15 to 36 weeks of gestational age (GA).

\begin{tabular}{|c|c|c|c|c|c|}
\hline GA & $\begin{array}{c}\text { No. of } \\
\text { Cases }\end{array}$ & $\begin{array}{c}\text { Mean FTL } \\
\pm \text { SD }\end{array}$ & $\begin{array}{c}\text { Mean BPD } \pm \\
\text { SD }\end{array}$ & Mean FL \pm SD & Mean AC \pm SD \\
\hline 15 & 4 & $17.50 \pm 1.29$ & $30.00 \pm 1.41$ & $15.75 \pm 1.70$ & $95.00 \pm 3.82$ \\
\hline 16 & 4 & $19.75 \pm 0.50$ & $32.75 \pm 1.89$ & $20.50 \pm 0.57$ & $104.0 \pm 2.82$ \\
\hline 17 & 4 & $20.00 \pm 0.81$ & $37.25 \pm 0.95$ & $23.25 \pm 0.95$ & $111.2 \pm 6.99$ \\
\hline 18 & 5 & $22.60 \pm 2.96$ & $40.60 \pm 0.89$ & $27.80 \pm 0.44$ & $116.4 \pm 4.09$ \\
\hline 19 & 4 & $25.75 \pm 0.50$ & $45.25 \pm 0.95$ & $30.50 \pm 1.00$ & $124.5 \pm 2.51$ \\
\hline 20 & 6 & $26.66 \pm 1.96$ & $47.66 \pm 0.81$ & $33.33 \pm 1.21$ & $144.0 \pm 4.19$ \\
\hline 21 & 4 & $28.00 \pm 0.81$ & $55.00 \pm 0.81$ & $34.00 \pm 0.81$ & $155.0 \pm 2.58$ \\
\hline 22 & 5 & $30.20 \pm 1.09$ & $56.80 \pm 0.83$ & $37.20 \pm 1.30$ & $173.2 \pm 2.77$ \\
\hline 23 & 4 & $32.50 \pm 1.00$ & $58.00 \pm 0.81$ & $40.66 \pm 1.00$ & $181.0 \pm 2.58$ \\
\hline 24 & 5 & $34.80 \pm 0.83$ & $61.00 \pm 1.41$ & $42.60 \pm 0.89$ & $196.2 \pm 3.63$ \\
\hline 25 & 4 & $35.75 \pm 0.50$ & $62.00 \pm 1.41$ & $45.50 \pm 1.00$ & $200.7 \pm 4.85$ \\
\hline 26 & 5 & $35.80 \pm 2.28$ & $65.20 \pm 1.64$ & $49.20 \pm 1.30$ & $216.4 \pm 5.77$ \\
\hline 27 & 4 & $36.25 \pm 2.06$ & $65.00 \pm 1.15$ & $51.50 \pm 1.00$ & $225.5 \pm 5.00$ \\
\hline 28 & 6 & $37.33 \pm 1.21$ & $71.66 \pm 3.07$ & $54.00 \pm 2.52$ & $231.1 \pm 11.5$ \\
\hline 29 & 5 & $41.20 \pm 1.09$ & $74.80 \pm 0.83$ & $54.40 \pm 1.14$ & $255.4 \pm 5.45$ \\
\hline 30 & 5 & $43.40 \pm 1.34$ & $75.00 \pm 1.00$ & $57.40 \pm 0.89$ & $272.8 \pm 3.34$ \\
\hline 31 & 4 & $45.50 \pm 2.38$ & $78.75 \pm 0.95$ & $58.75 \pm 0.95$ & $271.5 \pm 5.97$ \\
\hline 32 & 5 & $47.00 \pm 2.00$ & $79.20 \pm 0.83$ & $62.40 \pm 2.07$ & $288.2 \pm 9.70$ \\
\hline 33 & 4 & $49.00 \pm 3.46$ & $83.50 \pm 2.51$ & $63.00 \pm 2.58$ & $294.0 \pm 3.74$ \\
\hline 34 & 4 & $51.25 \pm 0.95$ & $85.00 \pm 0.81$ & $66.25 \pm 0.50$ & $304.0 \pm 4.32$ \\
\hline 35 & 4 & $58.75 \pm 4.78$ & $87.25 \pm 1.50$ & $69.25 \pm 1.70$ & $312.7 \pm 3.40$ \\
\hline 36 & 5 & $64.40 \pm 3.28$ & $89.80 \pm 1.48$ & $72.60 \pm 1.34$ & $325.6 \pm 6.22$ \\
\hline
\end{tabular}

Table 2: Predicted values of various parameters (FTL, BPD, FL, AC)

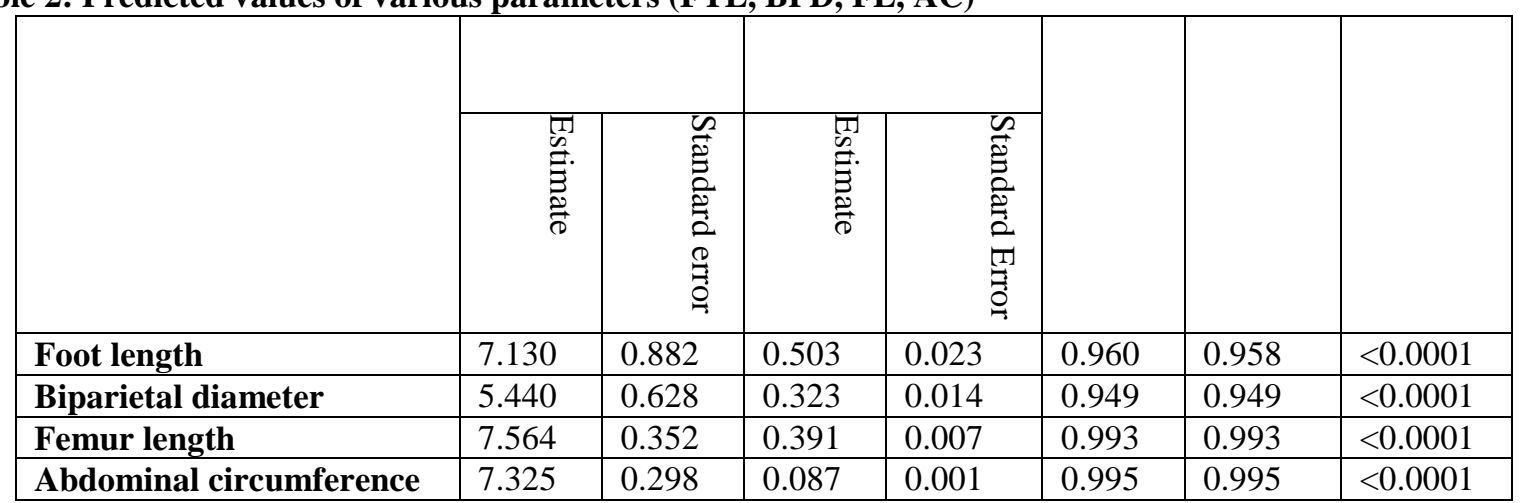

Table 3: Comparison of mean tibial length of present study with that of E.P. Issel, C. Exacoustos, Lyn S, Chitty

\begin{tabular}{|c|c|c|c|c|}
\hline & Present study & E.P.Issel & C,Exacoustos & Lyn S.Chitty \\
\hline 15 & 10.25 & - & 16.00 & 14.10 \\
\hline 16 & 15.25 & - & 20.00 & 16.90 \\
\hline 17 & 19.75 & 22.00 & 22.00 & 19,90 \\
\hline 18 & 24.40 & 23.00 & 23.00 & 22.80 \\
\hline 19 & 28.00 & 26.00 & 26.00 & 25.70 \\
\hline 20 & 31.00 & 29.00 & 29.00 & 28.50 \\
\hline 21 & 35.75 & 32.00 & 32.00 & 31.20 \\
\hline 22 & 37.40 & 33.00 & 33.00 & 33.80 \\
\hline 23 & 41.50 & 37.00 & 37.00 & 36.40 \\
\hline
\end{tabular}




\begin{tabular}{|l|l|l|l|l|}
\hline 24 & 42.40 & 39.00 & 39.00 & 38.80 \\
\hline 25 & 44.50 & 41.00 & 40.50 & 41.00 \\
\hline 26 & 46.40 & 43.00 & 43.00 & 43.20 \\
\hline 27 & 48.25 & 45.00 & 45.00 & 45.30 \\
\hline 28 & 50.60 & 46.00 & 46.00 & 47.30 \\
\hline 29 & 52.80 & 49.00 & 48.00 & 49.20 \\
\hline 30 & 55.40 & 50.00 & 49.50 & 51.00 \\
\hline 31 & 57.50 & 52.00 & 52.00 & 52.70 \\
\hline 32 & 60.50 & 55.00 & 55.00 & 54.40 \\
\hline 33 & 62.50 & 56.00 & 55.00 & 55.90 \\
\hline 34 & 65.50 & 57.00 & 57.00 & 57.50 \\
\hline 35 & 68.50 & 59.00 & 59.00 & 58.90 \\
\hline 36 & 70.80 & 61.00 & 60.00 & 60.30 \\
\hline
\end{tabular}

Table 4: Comparison between values of foot length of present study with previous studies

\begin{tabular}{|c|c|c|c|c|c|c|}
\hline GA & $\begin{array}{l}\text { Present Study } \\
\quad(2013)\end{array}$ & $\begin{array}{c}\text { Family } \\
\text { Practice } \\
\text { Notebook }\end{array}$ & $\begin{array}{c}\text { Molly S. } \\
\text { Chatterjee et al } \\
(1994)\end{array}$ & $\begin{array}{l}\text { Andrzej M. } \\
\text { bulandra } \\
\text { et al (2003) }\end{array}$ & $\begin{array}{c}\text { Rajesh } \\
\text { Bardale } \\
\text { et al (2008) }\end{array}$ & $\begin{array}{c}\text { Jowita Wozniak } \\
\text { et al (2009) }\end{array}$ \\
\hline 15 & $17.50 \pm 1.29$ & 18 & 20 & $19.75 \pm 1.05$ & \multirow[t]{2}{*}{$21.4 \pm 0.88$} & - \\
\hline 16 & $19.75 \pm 0.50$ & 20 & 22 & $18.94 \pm 1.92$ & & $10.3 \pm 2.8$ \\
\hline 17 & $20.00 \pm 0.81$ & 23 & 25 & $22.63 \pm 2.47$ & \multirow{4}{*}{$32.1 \pm 0.54$} & - \\
\hline 18 & $22.60 \pm 2.96$ & 26 & 27 & $24.70 \pm 1.96$ & & - \\
\hline 19 & $25.75 \pm 0.50$ & 29 & 30 & $29.19 \pm 2.62$ & & - \\
\hline 20 & $26.66 \pm 1.96$ & 33 & 32 & $30.90 \pm 4.91$ & & $17.8 \pm 3.8$ \\
\hline 21 & $28.00 \pm 0.81$ & 36 & 35 & $35.38 \pm 2.91$ & \multirow{4}{*}{$42.6 \pm 0.45$} & - \\
\hline 22 & $30.20 \pm 1.09$ & 39 & 37 & $39.01 \pm 2.05$ & & - \\
\hline 23 & $32.50 \pm 1.00$ & 42 & 40 & $43.16 \pm 3.91$ & & - \\
\hline 24 & $34.80 \pm 0.83$ & 45 & 42 & $45.80 \pm 4.51$ & & $26.6 \pm 6.6$ \\
\hline
\end{tabular}

Graph 1: Shows a plot of mean tibial length verses gestational age. The graph shows a linear increase of tibial length as pregnancy progresses from 15 weeks to 36 weeks

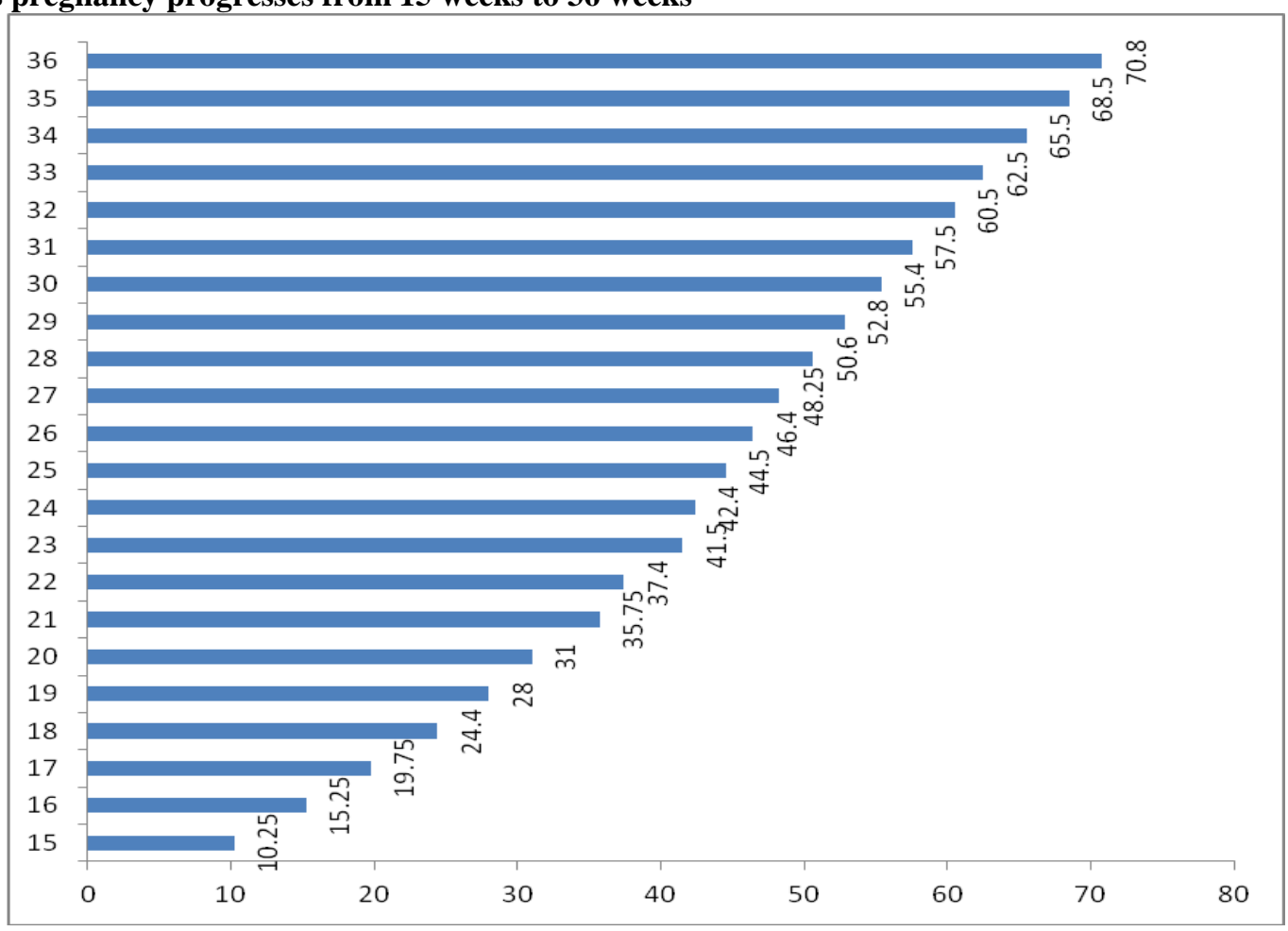




\section{Graph 2: Shows a comparative plot between mean TL, FL, BPD, AC. Graph shows more linear increase of} $\mathrm{BPD}, \mathrm{AC}, \mathrm{FL}$ as compared to tibial length as pregnancy progresses from 15 weeks to 36 weeks

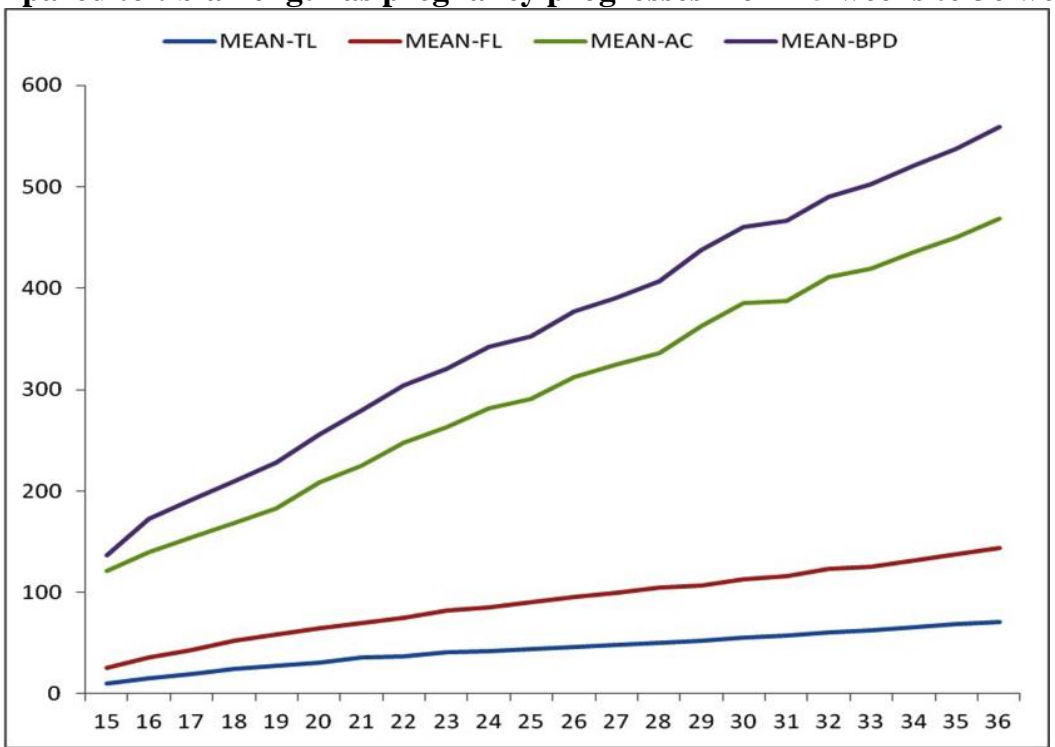

\section{Discussion}

Now a days determining the gestational age by ultrasonography has become an integral part of obstetric practice. Previously, the biparietal diameter (BPD) was considered as a reliable method of determining gestational age. While the BPD was the first fetal parameter to be clinically utilized in the determination of fetal age in the second trimester, later studies have evaluated the use several other biometric parameters including head circumference (HC), abdominal circumference (AC), femur length (FL), Tibia length, Foot length, ear size, orbital diameters, cerebellum diameter and others. ${ }^{1}$

The present study was done in 100 pregnant women having singleton apparently normal foetuses between 15 to 36 weeks of gestation and subjects having any medical pathology were excluded from study. Fetal tibia length and other parameters measured were BPD, FL, and AC. Statistical analysis of the observations showed R2 and standard deviation of study significant. In the present study R value is 0.991 and Standard deviation is 0.874 .

C. Exacoustos, et al. studied 2317 normal pregnant women by ultrasonographic scan linear growth of all limb bones between 13 and 40 weeks of gestation. They found $\mathrm{R}$ value 0.994 and standard deviation 1.619 for tibial length in their study. With compare to our study standard deviation is much less but $\mathrm{R}$ values are very much similar. ${ }^{6}$

Lyn S. Chitty et al studied all long bones of 663 fetuses between gestational age of 12 to 42 weeks, they found Standard deviation 0.049. ${ }^{7}$

Juozas K., et al did a prospective cross sectional study on limb length of 6557 pregnant women between 12 to 42 weeks of gestational age and obtained $R$ value $0.999 .^{8}$
Zeba Khan, et al (2006) found most of long bones showed maximum growth rates between $4^{\text {th }}$ to $6^{\text {th }}$ months. The rate of growth for femur during aforementioned period was relatively higher i.e. $>12 \mathrm{~mm}$ per month. Tibial growth was maximum (30.50 mm per month) during $5^{\text {th }}$ month. ${ }^{9}$

In present study the values of tibial length were lower or higher because there was a significant racial and socioeconomic difference between individuals of the present study and other studies as per Table 3 . The differences in the readings may also be attributed to number of operators, type of study (cross-sectional verses longitudinalstudy), estimate of gestational age (rounded offverses exact) and quality of ultrasound machine (older or newer).

Fetal foot length have good correlation with gestational age with correlation coefficient 0.960 with $\mathrm{p}<0.0001$ in present study. Goldstein I et $\mathrm{al}^{10}$ found a significant correlation between fetal foot length and gestational age $(r=0.9, p$ less than 0.0001) and between fetal foot length and femur length $(r=0.9$, $p$ less than 0.0001) however in the present study correlation coefficient between fetal foot length and gestational age $(r=0.960, p<0.0001)$ and between fetal foot length and femur length $(r=0.948, p<0.0001)$ was found to be higher, thus making the present study more reliable.

The variation in values in our study are lower or higher as shown in Table 4 is due to significant racial and socioeconomic differences between individuals of the present study and that of previous studies. Table 4 shows the comparison between the values of Fetal Foot Length of present study with standard values of Family Practice Notebook maintained by Scott Moses, MD, a board-certified Family Physician practicing in Lino Lakes, Minnesota ${ }^{11}$ with previous studies done by 
Molly S. Chatterjee in, ${ }^{12}$ Andrzej M. Bulandra, ${ }^{13}$ Rajesh Bardale $^{14}$ and Jowita Wozniak. ${ }^{15}$

R. Mhaskar et al in 1989 showed a strong correlation on comparison of linear regression of foot length versus gestational age with an $\mathrm{r} 2$ value of 0.84 ( $\mathrm{P}$ $<0.001$ ) which is comparatively much lesser than the present study showing $\mathrm{r} 2$ value of $0.960(\mathrm{p}<0.0001)$ although both studies are consistent. ${ }^{16}$

Ji E K et al in 2001 showed that fetal foot length during the second trimester of a normal pregnancy in Korean women is a reliable parameter for use in the assessment of gestational age. The normogram depicted in his study serve as a useful adjunct in the screening of chromosomal abnormality or skeletal dysplasia among Koreans. ${ }^{17}$

Andrzej M. Bulandra et al in 2003 demonstrated that the value of the correlation index between foot length and femur length was 0.91 , while between foot length and humerus length was 0.96 and between foot length and fetal age was 0.94 in close association with our study. ${ }^{17}$

M.C. Lutterodt et al in 2009 seen foot length linearly to embryonic and fetal age, and was unaffected by gender, environmental tobacco smoke, maternal smoking and alcohol consumption. ${ }^{18}$

The results of the present study compared with previous researches we concluded that the present study is concordant with that of previous studies (Table 4). Never the less high correlation coefficient (0.960) and comparatively lesser standard error (1.3) make this study more reliable.

Since the present study also compared the foot length with the more recognizable previously used parameters such as biparietal diameter, femur length and abdominal circumference, a higher association was found between femur length, abdominal circumference with that of gestational age as compared with foot length and biparietal diameter.

\section{Conclusion}

In normally developing fetus the fetal tibial and foot lengths increases with an advancing gestational age.

The findings of present study deduce that the fetal tibia length may also be used as one of the good markers for the determination of gestational age and further the fetal foot length is a good marker for determination of gestational age in cases of femur achondroplasia, dolichocephaly or brachycephaly especially in the late second and third trimesters of pregnancy.

\section{References}

1. Robin B. Kalish, Frank Chervenak. Sonographic Determination of Gestational Age. Timisoara Medical Journal 2009;59(2):254-8.

2. Streeter GL. Weight, sitting height, head size, foot length, and menstrual age for the human embryo. Contrib Embryol 1920;11:143-70.
3. Lower Limb Embryology Gross Morphologic Overview of Lower Limb Development. Updated: Oct 21, 2016. Available as https://emedicine.medscape.com/article/1291712overview.

4. Mercer BM, Sklar S, Shariatmadar A, Gillieson MS and D Alton ME. Fetal foot length as a predictor of gestational age. Am J Obstet Gynecol 1987;156:350-5.

5. E. P. Issel. Ultrasonic measurement of the growth of fetal limb bones in normal Pregnancy. J Perinat Med 1985;13:305-13.

6. C. Exacoustos, P. Rosati, G. Rizzo, D. Arduini Ultrasound measurements of fetal limb bones. Ultrasound Obstet Gynecol 1991;1:325-30.

7. Lyn S. Chitty, Douglas G. Altman. Charts of fetal size: Limb bones. Brit J Obste Gynae 2002;109:919-29.

8. Juos Kurmanavicius, Eileen M. Wright, Patrick Royston, Roland Zimmermann, Renate Huch, Albert Huch, Joseph Wisser. Fetal ultrasound biometry: 2. Abdomen and femur length Reference values. Brit J Obst Gynae 1999;106:136-43.

9. Zeba Khan, Nafis Ahmad Faruqi. Determination of Gestational Age of Human Foetuses from Diaphyseal Lengths of Long Bones- A Radiological Study. Anat Soc India 2006;55:67-71.

10. Goldstein I, Reece EA, Hobbins JC. Sonographic appearance of the fetal heel ossification centers and foot length measurements provide independent markers for gestational age estimation. Am J Obste Gynecol 1988;59(4):923-6.

11. Family Practice Notebook. Scott Moses. Lino Lakes, Minnesota. Available as http://fpnotebook.com/OB/Antepartum/FtlFtMsrmnt.htm

12. Molly S. Chatterjee, Luis A. Izquierdo, Bobby Nevils, George J. Gilson, Cesar Barada. Fetal foot: evaluation of gestational age. 1994.available as http://www.thefetus.net.

13. Andrzej M Bulandra,Malgorzata Kuczera, Joanna Machnik, Bartlomiej M Kuczera, Jerzy S Gielecki. Is manual foot length measurement of comparable value to ultrasound femur and humerus measurement in anatomical studies for the assessment of fetal age. Folia Morphol 2003;63(2):203-7.

14. Rajesh Bardale MD, Vaibhav Sonar MD. Assessment of Gestational Age from Hand and Foot Length. Ind Journal Foren Medic Path 2008;1(2):47-51.

15. Jowita Wozniak, Alicja Kedzia, Krzysztof Dudek. Fetal foot length-width- a new parameter in foetal age analysis. Archi Perin Medic 2009;15(4):215-21.

16. Mhaskar R, Agarwal N, Takkar D, Buckshee $\mathrm{K}$, Anandalakshmi, Deorari A. Foetal foot length as a parameter for assessment of gestational age. Int $\mathrm{J} \mathrm{Obs}$ Gynae 1989;29(1):35-8.

17. Ji EK. Ultrasonographic Measurement of Fetal Foot Length and Femur/Foot Length Ratio in Second Trimester of Normal Pregnancy in Korean Women. $J$ Kore Radiol Soc 2001;44(6):715-9.

18. M.C. Lutterodt, M. Rosendahl, C. Yding Anderson, S.O. Skouby. Age determination enhanced by embryonic foot bud and foot plate measurements in relation to Carnegie stages, and the influence of maternal cigarette smoking. Hum Reprod 2009;24(8):1825-33. 